\title{
REVIEW
}

\section{Heart Rate Variability in Newborns}

\author{
K. JAVORKA ${ }^{1,2}$, Z. LEHOTSKA $^{3}$, M. KOZAR ${ }^{3}$, Z. UHRIKOVA $^{3}$, B. KOLAROVSZKI ${ }^{4}$, \\ M. JAVORKA ${ }^{1,2}$, M. ZIBOLEN ${ }^{3}$
}

${ }^{1}$ Department of Physiology, Jessenius Faculty of Medicine in Martin, Commenius University in Bratislava, Martin, Slovakia, ${ }^{2}$ Biomedical Center Martin, Jessenius Faculty of Medicine in Martin, Commenius University in Bratislava, Martin, Slovakia, ${ }^{3}$ Clinic of Neonatology Jessenius Faculty of Medicine in Martin, Commenius University in Bratislava and University Hospital, Martin, Slovakia, ${ }^{4}$ Clinic of Neurosurgery, Jessenius Faculty of Medicine in Martin, Commenius University in Bratislava and University Hospital, Martin, Slovakia

Received April 30, 2017

Accepted April 30, 2017

\section{Summary}

Heart rate (HR) and heart rate variability (HRV) in newborns is influenced by genetic determinants, gestational and postnatal age, and other variables. Premature infants have a reduced HRV. In neonatal HRV evaluated by spectral analysis, a dominant activity can be found in low frequency (LF) band (combined parasympathetic and sympathetic component). During the first postnatal days the activity in the high frequency (HF) band (parasympathetic component) rises, together with an increase in LF band and total HRV. Hypotrophy in newborn can cause less mature autonomic cardiac control with a higher contribution of sympathetic activity to HRV as demonstrated by sequence plot analysis. During quiet sleep (QS) in newborns HF oscillations increase - a phenomenon less expressed or missing in premature infants. In active sleep (AS), HRV is enhanced in contrast to reduced activity in $\mathrm{HF}$ band due to the rise of spectral activity in LF band. Comparison of the HR and HRV in newborns born by physiological vaginal delivery, without (VD) and with epidural anesthesia (EDA) and via sectio cesarea (SC) showed no significant differences in HR and in HRV time domain parameters. Analysis in the frequency domain revealed, that the lowest sympathetic activity in chronotropic cardiac chronotropic regulation is in the VD group. Different neonatal pathological states can be associated with a reduction of HRV and an improvement in the health conditions is followed by changes in HRV what can be use as a possible prognostic marker. Examination of heart rate variability in neonatology can provide information on the maturity of the cardiac chronotropic regulation in early postnatal life, on postnatal adaptation and in pathological conditions about the potential dysregulation of cardiac function in newborns, especially in preterm infants.

\section{Key words}

Newborn - Premature newborn - Heart rate variability • Autonomic nervous system $\bullet$ Postnatal adaptation

\section{Corresponding author}

K. Javorka, Department of Physiology and Biomedical Center Martin, Jessenius Faculty of Medicine in Martin, Mala Hora 4C, 03601 Martin, Slovakia. E-mail: javorka@jfmed.uniba.sk

\section{Introduction}

Regulation of the heart in fetal and neonatal period has its own peculiarities, based on morphological, biochemical and other differences not only in cardiovascular system (CVS), but also in the central nervous system (CNS).

Premature/preterm newborns are a specific group of newborns with immaturity of cardiovascular structures, including regulatory circuits and systems.

Intracardiac autoregulation in fetuses as well as in newborns is functioning, but the relationship between end-diastolic volume and force of contraction (Starling's Law) is shifted to the upper limit of the functional curve (Rudolph 1986). Homeometric 
(frequency dependent) mechanism - Bowditch effect is more important in fetuses and newborns. The dominance of "the frequency control" is responsible for the fact that changes in heart rate are particularly accompanied by changes in cardiac output. This explains why increased attention should be paid to the study of the chronotropic cardiac regulation of newborns.

Extracardiac - nervous regulation: Peculiarities of the cardiac nervous control during early postnatal life are based mainly on the maturity/immaturity of the autonomic nervous system (ANS). During ontogenesis an early proper function of receptors even before the presence of mature nerve fibers was demonstrated (Sperelakis and Pappano 1983). The typical structure of the adrenergic nerve terminals in the atria and ventricles of human fetuses was found in 28th - 29th week of the gestation (Danihel et al. 1989) corresponding to the age of very preterm newborn.

Maturity of the parasympathetic innervation of the heart in experiments depends on the gestational age and species of animal. For example, during the first days of postnatal life in the rats have a weak parasympathetic tone, which is reflected in a very high heart rate. However, vagal stimulation can elicit negative chronotropic effects (Mills 1978, Vlk 1989). A similar situation can be found in humans.

Baroreflexes: Baroreflex sensitivity in newborns, mainly in preterm, is reduced (Drouin et al. 1997, Gourney et al. 2002, Andriessen et al. 2005, Yiallorou et al. 2010, Haskova et al. 2017). Potentially, reduced baroreflex sensitivity could increase short-term cardiovascular instability and thus increase risk of neural injury (Bennet et al. 2012).

Chemoreflexes: Cardiac chronotropic reactions in newborns during asphyxia depends on many factors including maturity, baroreflex sensitivity, changes in the pattern of ventilation (stopping of breathing movements or compensatory increased ventilatory efforts, etc.). Chronotropic reactions to hypercapnia, e.g. elicited by inhalation of $4 \% \mathrm{CO}_{2}$ depend on maturity of human newborns. The HR of term infants increased promptly during $\mathrm{CO}_{2}$ exposure, but this response was inhibited and delayed in premature newborns (Cohen et al. 2007).

However, bradycardia is a dominant reaction to aphyxia in newborns similarly to fetuses occuring after a period of tachycardia due to significant inhibitory effect of hypoxia on central structuresof the brain stem controlling blood circulation.

\section{Heart rate variability in newborns}

\section{Heart rate variability}

Heart rate variability - fluctuations around the mean heart rate value - is a reflection of the active complex regulation of the heart. Data for HRV recording can be obtained in two ways: short-term variability is based usually on 5 - 10 min lasting beat-to-beat (R-R intervals) ECG recordings, long-term variability is analysed from $24 \mathrm{~h}$ Holter recording of ECG signal.

The short-term HRV reflects a dynamical cardiac regulation depending mainly on the activity of the autonomic nervous system (ANS) as well as an ability of the organ (heart) to react to the regulatory commands. This is why an evaluation of the short-term HRV provides an important information about maturation and current dynamical balance of the ANS in newborns. Chronotropic regulation of the heart seen in the short-term variability through ANS is a very dynamical fast action, especially via the parasympathetic nerves. An increase or a decrease of the activity in the vagal rami cardiaci is manifested almost beat-to-beat, in newborns (with heart rate around 120/min), each second/third contraction of the heart. Norepinephrine has much slower metabolism and this is why the sympathetic activity mediates only slower but longer lasting effects on the heart rate and heart rate variability.

The mechanisms of short-term heart rate control include local mechanical effects, changes in intrathoracic pressure, acting directly on the sinoatrial node and other structures of the heart and vessels followed by changes in perfusion and venous return (Javorka et al. 2008).

\section{Data acquisition and analysis}

Heart rate variability is very useful and easily recorded phenomenon that can be analyzed in research as well as in clinical practice. Usefulness and accessibility of the HRV examination in neonatology are based on the fact that cardiac chronotropic regulation for a newborn is crucial; and that time series of the RR intervals can be easily obtained by ECG devices or by special (HRV) systems.

In our studies, the neonatal ECG analog signal was recorded by thoracic ECG lead of portable devices for continuous heart rate recording VarCor PF6 and VarCor PF7 Neonatal (Dimea, Czech Republic) with a sampling frequency of $1,000 \mathrm{~Hz}$ and a telemetric transmission of data to $\mathrm{PC}$.

The recorded time series of RR intervals can be 
analyzed by various methods. The most commonly used methods for analysis include a standard linear time and frequency domain measures (Heart Rate Variability 1996). In the frequency domain, spectral analysis using Fast Fourier Transform enables to determine a spectral power in low frequency (LF) band reflecting the sympathetic (parasympathetic, and baroreflex) activity in the standard frequency range LF: $0.04-0.15 \mathrm{~Hz}$, and power in high frequency band (HF) determined mainly by the respiratory sinus arrhythmia mediated via parasympathetic nervous system. The range of this band for neonatal purposes is extended up to $1.5 \mathrm{~Hz}$ considering higher respiratory rate in newborns, mainly in premature.

Standard linear HRV analysis by spectral analysis provides a relevant information about periodic oscillations in heart rate. The analysis is most useful when analyzing periodic oscillations, but in the complex control system output analysis - as in the case of human heart rate oscillations where nonlinear components are also included (Czippelova et al. 2015) - it has only a limited value. Therefore, for the HRV analysis in newborns were recently rarely applied also nonlinear dynamics based methods, including Poincaré plot, sequence plot, Approximate Entropy (ApEn), Multiscale Entropy (MSE), symbolic dynamics methods and time irreversibility analysis (Porta et al. 2001, Porta et al. 2007, Javorka 2006, Czippelova et al. 2015).

\section{Determinants of heart rate variability in newborns}

\section{Heart rate variability and genetics}

Heritability can play a role in between-subjects differences in cardiac chronotropic regulation in newborns potentially influencing all structures involved in cardiac control development.

Singh et al. (1999) found in a large number of families that genetic factors are responsible for $13-23 \%$ of interindividual variability. Correlation between siblings` HRV measures was significantly higher than between spouses. Joint effect of living in one household had a much lower influence of only 1 to $13 \%$. Stronger genetic determination of RR intervals was found by other authors (Kupper et al. 2005) in twins and siblings. The genetic influences proportion on heart rate and respiratory sinus arrhythmia were $37-48 \%$ and $40-55 \%$, respectively.

\section{Intraindividual stability of heart rate and heart rate variability}

DiPietro et al. (2000) found that some fetal circulation characteristics and maternal relevant physiological parameters explain from 40 to $48 \%$ of the heart rate (HR) and heart rate variability (HRV) in newborns and infants up to the end of the first year of life. Increased fetal heart rate was reflected in a higher mean heart rate in the newborns. Significant intraindividual stability of HR and HRV were found not only in the prenatal period (observation in the period between 20th and 38th gestation week) but up to the age two years (Thomas et al. 1989). It indicates obvious "inertia" of cardiovascular characteristics - tracking phenomenon - which is transmitted from prenatal to postnatal life.

\section{Heart rate variability as a predictor of developmental outcome}

DiPietro et al. (2007) hypothesized that slower HR and higher HRV would be reflected in more advanced development of functions in early childhood. They found that fetuses exhibiting slower and more variable heart rates had at age of 2 years significantly higher Mental and Psychomotor Development Indices (MDI, PDI) and they had better speech development than those with faster $\mathrm{HR}$ and reduced HRV. Similar results - an association between vagal tone and neonatal attentional orientation have been shown by Feldman (2006), between HRV and MDI scores at the age of 1 year by Richards (1989), and between respiratory sinus arrhythmia and standardized cognitive test scores in middle childhood (El-Sheikh and Buckhalt 2005).

These data suggest that HRV during prenatal/perinatal life correspond (to some extent) with the maturation of CNS (ANS) and mental development of individuals.

\section{Heart rate, heart rate variability and gestational age}

Mature newborns are equipped well for rapid adaptation to the extrauterine life. However, premature newborns, mainly very premature, have not yet completed the development of the autonomic innervation of the heart. That's why cardiac chronotropic regulation in premature newborns is typical by very low 
parasympathetic tone at rest, what is manifested in higher heart rate. Furthermore, premature infants can have altered autonomic control of cardiovascular system which can manifest as abnormalities in HRV and baroreflexes (e.g. Fyfe et al. 2014, Fyfe et al. 2015).

Gestational age in preterm infants significantly correlates with HR and HRV parameters (e.g. Golder et al. 2013). The lower is gestational age, the higher is mean HR, lower HRV and blood pressure. Very likely this finding is related to the degree of maturity of the autonomic nervous system (Van Ravenswaaij-Arts et al. 1994, Mehta et al. 2002, Kantor et al. 2003). We suggest, this phenomenon has its own physiological importance, higher HR in premature newborns is beneficial to cover higher metabolic requirements on the basis of preferential cardiac homeometric mechanism for the cardiac output control.

During the first postnatal days in healthy term and preterm newborns is in the HRV dominant activity of low-frequency band (LF) determined partially but significantly by sympathetic component (Aarimaa and Oja 1988). The biggest difference between HRV in term and preterm newborns, immediately after birth, is spectral activity in the HF band, which is very low or is absent in premature subjects. It is seen even during sleep, when mature newborns increase activity in the HF band, in the premature infants, this increase is lacking. This is probably due to different pattern of breathing due to immaturity of the organization of sleep stages and parasympathetic division of the ANS. Maturation of the ANS is then accompanied by an increase of the parasympathetic (HF) activity (Curzi-Dascalova et al. 1989, Porges et al. 1999, Longin et al. 2006).

However, in human newborns even in the first postnatal days can be elicited cardiac inhibitory reflexes, for example oculocardiac and Cushing reflex (Javorka and Zavarska 1978, Veerappan et al. 2000). We suggest, the inhibitory reflexes resulting in transient bradycardia may have a physiological role in improvement of coronary perfusion during physiological delivery when the fetal head is squeezed and retroorbital and intracranial pressures are increased.

\section{Heart rate, heart rate variability and early postnatal age}

Postnatal age. Heart rate (HR) declines with increasing postnatal age, whereas in preterm babies the mean HR remains in higher values for longer time.
Makarov and co-workers (2010) studied changes of HR in healthy term newborns during first 4 days of life by Holter's monitoring. Significant decrease in mean HR values especially during second day have been observed. In preterm healthy neonates (28th - 36th week of gestation) this decrease was smaller and the higher mean HR persisted until to the end of the first week of life.

Heart rate variability (HRV) significantly increases in all bands reflecting sympathetic and parasympathetic regulation in the first three postnatal days (Kantor et al. 2003). The massive increase of HRV parameters in full-term healthy newborns during the first 4 days was confirmed by spectral analysis as well as by Poincaré and Sequence Plots (Lehotska et al. 2007). We observed up twofold increase in the time and frequency domain HRV parameters, as well as an increase in the size of Poincaré Plot during the early postnatal period.

A possible explanation for the increase in HRV may be effect of the onset of air breathing with enhancement of the respiratory sinus arrhythmia, gradual withdrawal of postnatal stress and postnatal acceleration of maturation. The most likely is the combination of all factors. It seems that the withdrawal of the postnatal stress is not crucial because the most significant part of the increase in HRV is the low-frequency (LF) band.

Postconceptional age (PCA) is calculated as gestational age plus postnatal age $(\mathrm{PCA}=\mathrm{GA}+\mathrm{PNA})$, so it is a function of both, gestational and postnatal ages. HRV in relation to postconceptional age was studied by Yang et al. (2007). They found that the advance in postconceptional age exerts a significant influence over HRV with a steady increase in total power and spectral powers in both LF and HF bands, along with a progressive decline of $\mathrm{LF} / \mathrm{HF}$ ratio (sympathovagal balance). Newborns of more than 36 weeks PCA demonstrated a significantly greater HRV - activity of ANS in chronotropic cardiac regulation - than younger group. However, the maturation of sympathovagal balance shown by the LF/HF ratio needed to take two more weeks, because the cut-off age occurred at 38 weeks PCA. It means that newborns with PCA more than 38 weeks are relatively mature for neonatal conditions also in terms of sympathovagal balance.

\section{Heart rate variability and hypotrophy}

More authors studied HR and HRV in hypotrophic - small for gestational age (SGA) newborns and compared to the eutrophic - appropriate for 
gestational age (AGA) matched newborns. Galland et al. (2006) found no difference in baseline heart rate (HR) between SGA and AGA infants, although Spassov et al. (1994) reported that HR is higher in SGA newborns. Tendency for a higher mean heart rate in the early postnatal period was found also by Lehotska et al. (2007a).

SGA newborns had at rest the same HRV parameters as AGA infants, but once HR was controlled, differences between groups were found suggesting higher sympathetic and lower vagal tone in SGA infants. It can reflect a more immature autonomic nervous system.

Lehotska et al. 2007a and Lehotska et al. 2007b

found in both groups (eutrophic and hypotrophic) dominant sympathetic activity in the 1st day of life and in the 4th day was significant increase of HRV parameters of all time domain and frequency parameters. The results of the HRV standard analysis and the Poincaré Plot in the first and 4th postnatal days showed no substantial differences between eutrophic (AGA) and hypotrophic (SGA) newborns. Significant differences in the HRV were found between these two groups in the first postnatal day by Sequency plot. There was a reduced percentage in the 2 nd and 4th quadrant of the plot and increased the percentage of points in the 3 rd quadrant (reflecting sympathetic action) indicating higher sympathetic activity in hypotrophic compared to eutrophic newborns.

The results suggest that intrauterine growth retardation can be linked with immaturity of the ANS in cardiac regulation with typical higher sympathetic component seen in the HRV measures in SGA infants compared with AGA infants. This immaturity potentially can increase vulnerability of hypotrophic newborns to perinatal morbidity/mortality or later to sudden infant death syndrome - SIDS (Galland et al. 2006). Even at $11-12$ weeks of infant age, the sympathetic component of cardiac control is higher in infants who have experienced postnatal catch-up growth as in SGA (Meny et al. 1994), and sympathetic hyperactivity is a known risk factor for CVS disease.

\section{Heart rate, heart rate variability and gender in newborns}

In adulthood, there are gender differences in the mean heart rate and HRV. The differences are determined by functional and morphological status of the autonomic nervous system, cardiovascular system, effects of hormones, but also by different intensity and type of physical activity as well as by different body constitution. More studies have addressed the question of whether these gender differences in HR and HRV are already present at birth, or develop later.

The results of studies on gender differences in HR and HRV in newborns are controversial. Kero (1974) and Yang et al. (2007) in premature infants and Harper et al. (1976) and Andrasyova and Kellerova (1996) in term newborns and infants did not find significant gender differences in heart rate. On the other hand, Nagy et al. (2000) found that boys in alert but quiet state had lower mean heart rate (by 8 beats per min) compared with girls. We have obtained similar results (Lehotska et al. 2007b, Javorka 2006). The eutrophic male newborns tended to a higher value of RR intervals (RR intervals in boys: $501 \pm 13 \mathrm{~ms}$ ) compared to girls: $461 \pm 13 \mathrm{~ms}$; $\mathrm{p}=0.051$ ), i.e. lower mean HR (by 10 beats per min).

Parameters of heart rate variability between boys and girls were not different in linear and nonlinear parameters girls in the 1 st as well as in the 4 th postnatal day.

These results suggest that the gender-related differences in HR are already present at birth. Nagy et al. (2000) speculate that this higher HR in girls is for a compensation of differencies in stroke volumes which may be different. Further investigation is needed to clarify this problem.

\section{Heart rate variability and sleep}

Relationship between HR/HRV and different stages of the sleep in newborns was studied by several authors. Harper et al. (1976) and Porges et al. (1999) found in term newborns that during quiet sleep (non-REM) in comparison to the active sleep (REM) is lower heart rate, longer $R R$ intervals and higher amplitude of the respiratory sinus arrhythmia (RSA). During quite sleep newborns had lower values of HRV compared with waking state and active sleep (Harper et al. 1976).

Yiallourou et al. (2012) confirmed previous findings that resting HRV is increased during active sleep (AS) compared to quiet sleep (QS) in term infants and that resting HF spectral power is reduced in AS. They also shown thal LF and total spectral power is higher in AS, particularly in early postnatal life. These findings confirm that in AS in early infancy is dominant sympathetic activity and AS represents a time of 
heightened arousal (Galland et al. 2006).

During quiet sleep in mature newborns increases activity in the HF band what is missing in premature infants. Preterm infants exhibit lesser parasympathetic modulation of the heart, what together with other pecularities of the cardiovacular regulation may increase their risk of cardiovascular dysfunction later in life (Yiallourou et al. 2012, Yiallourou et al. 2013). This deficit is possibly associated with the immaturity of the sleep stages organization and of the autonomic nervous system. Maturation of CNS/ANS is then accompanied by an increase HRV together with an enhancement of parasympathetic (HF) activity (Curzi-Dascalova et al. 1989, Porges et al. 1999, Longin et al. 2006).

During childhood different types and stages of sleep differentiate well. In quiet non-REM sleep are marked signs of the increase of the parasympathetic tone also in heart rate and heart rate variability. Parasympathetic dominance and prolongation of RR intervals during non-REM sleep in subjects in the fifth decade of life decreases and later progressively disappears (Crasset et al. 2001).

\section{Heart rate variability and mode of delivery}

How delivery stress affects HR and HRV in newborns is still unexplained. Changes in HR and HRV after birth could be affected by mode of delivery, maternal anesthesia and many other factors like following care for the newborn. Several studies showed that spontaneously delivered newborns had significantly higher HR compared with neonates born by sectio cesarea (SC) or with maternal epidural analgesia (EDA) administration (Gonzales and Salirossas 1998). The most likely cause it could be an effect of medical administration and lower delivery stress after analgesia.

In contrast, Toth et al. (2002) presented significantly higher HR in spontaneously born neonates with EDA compared to neonates without administration of maternal analgesia. Duration of this higher HR in EDA group was only transient and lasts about $10 \mathrm{~min}$ after birth.

Kozar (2016) in clinical study consisting of 46 healthy full - term newborns born by physiological vaginal delivery without and with EDA and via SC measured HR and HRV between the first and the second hour after birth and in 3rd/4th postnatal day. No significant differences in heart rate (RR intervals) according to mode of delivery (physiological vaginal delivery, EDA, SC) were observed. There also were not significant differences in time domain parameters of the HRV. However, in the frequency domain was lower relative power of low-frequency band (LF\%) and higher relative power of high frequency band (HF\%) after physiological vaginal delivery in both measurements (1st and 3rd - 4th day). Explanation might be in anesthetic effect in neonates delivered by sectio cesarea as well as rapid reduction of delivery stress in spontaneously born babies. We suggest, it is necessary to take into consideration also differences in specialized care for newborns after physiological and surgical deliveries.

Similarly, Lehotska (2007) studied HR and HRV (spectral analysis - time and frequency domains) in eutrophic and hypotrophic (AGA and SGA) newborns regarding mode of delivery (physiological vaginal vs SC). Neither on the first nor on the fourth postnatal day significant differences were found in separate groups (AGA, SGA) as well as in whole group of children.

It seems that at present time the modern management of parturitions, use of effective and only a short time acting anesthetics guarantee equivalent postpartum neonatal adaptation, at least in terms of chronotropic regulation of the heart.

\section{Heart rate variability in some pathologies and during their treatments in newborns}

It seems, that evaluation of the HRV in newborns can also be used in various pathological situations and therapeutic interventions and it can have great potential for the future.

HRV in premature infants with severe respiratory distress syndrome (RDS) in the first five postnatal days was studied by Kero (1974). In children with RDS, heart rate variability was abnormally low during the whole studied period. Later was shown, that progressive increase in the HRV was a good prognostic sign (Nishida et al. 1981). In premature newborns with RDS there was not only reduced resting HRV, but also cardiovascular reflexes, e.g. oculocardiac and somatosympathetic (Javorka and Zavarska 1978), and elicitability of some defensive respiratory reflexes (Javorka et al. 1985).

To the mechanisms of the HRV reduction, besides immaturity of ANS and other systems like respiratory, whose immaturity is evident as a surfactant deficiency, could contribute changes in blood gases and acid-base balance. It was shown that reduced HRV is 
associated also with asphyxia, low Apgar scores and low $\mathrm{pH}$ at birth, and is attributed to CNS depression (Nishida et al. 1981, Maulik et al. 1983).

HRV reduction was also found in clinically significant patent ductus arteriosus (PDA). The mechanism of this HRV decrease may be in deteriorated myocardial oxygen supply, what also can affect HRV. The reduction of HRV was adjusted by closing the ductus arteriosus through administration of indomethacin, especially in those newborns with improvement of oxygenation (Prietsch et al. 1992). The authors emphasize that the HRV corresponds to oxygenation in the brain stem and recommend evaluation of the HRV as a useful tool for monitoring effects of PDA treatment.

Newborns as well as older children with congenital heart defects have usually reduced HRV depending on the type of defect and time factor (duration of the defect, age). For example, when congenital defect is associated with cardiac failure, there are higher levels of catecholamines and increased sympathetic activity, and all these factors will have a reflection in increase the ratio LF/HF. Successful surgical correction of the heart defects after the early postoperative period, when the HRV can be further reduced is accompanied by a gradual increase in HRV, especially of parasympathetic component (HF band). Monitoring of HRV may be one of the indicators assisting timing of surgical correction of heart defects, and monitoring its success (Butera et al. 2004).

In newborns with coarctation of the aorta $(\mathrm{CoA})$ were found cardiovascular autonomic dysfunction, together with elevated blood pressure, depressed baroreceptor sensitivity and heart rate variability (Polson et al. 2006). In this study, frequency domain analysis showed a proportional decrease in total power and in both powers in the LF and HF bands, thus without changes in $\mathrm{LF} / \mathrm{HF}$ ratio.

Early diagnosis through HRV analysis what is very sensitive (but non-specific) tool could help to diagnose the onset of a disease/disorder or even the threat of this onset. HRV changes have been rarely studied prior the clinical manifestation of the disease. An example is neonatal sepsis in which was found the HRV reduction observable as early as $24 \mathrm{~h}$ before the clinical symptoms (Griffin and Moorman 2001).

These results led to the construction of the device HRC (HeRO) monitor based on the ECG from standard bedside monitor and special software continuously calculating HRC index. The index incorporates reduced HRV and transient decelerations, and HeRO monitor continuously displays the HRC index. Abnormal HRC strongly associated with late-onset sepsis in preterm infants and can detect biological changes associated not only with sepsis (Griffin and Moorman 2001, Griffin et al. 2007) but also with necrotizing enterocolitis (NE) up to a day before clinicians recognize that a patient is ill (Stone et al. 2013).

Mechanism of HRV reduction in neonatal sepsis is unknown. It is hypothetized that cytokines affect the transmission of signals and the signals may interfere with the sympathetic and parasympathetic signals. Levels of cytokines (IL-1, IL-6) were elevated already two days before the clinical manifestation of sepsis, which suggests that it may be responsible for changes HRV. Interestingly, HRV was reduced by endotoxin infusion in human volunteers (Godin et al. 1996).

Effects of hyperbilirubinemia in newborns and its treatment by phototherapy on cardiovascular parameters including the HRV were studied very rarely. Uhrikova et al. (2015) hypothesized that the hyperbilirubinemia via neurotoxicity of bilirubin could influence the cardiovascular control in newborns. Conventional analysis in time and frequency domains of the HRV did not show any differences but several indices based on nonlinear dynamics detected a subtle shift in cardiovascular control towards increased parasympathetic activity and/or sympathetic activity decrease in jaundiced newborns.

Phototherapy of the jaundiced newborns was accompanied by a slight increase in heart and respiratory rate and in a decrease in systemic blood pressure (Javorka and Zavarska 1990).

Linear analysis (time and frequency domains) of the HRV did not reveal any significant changes during and after phototherapy. However, the application of nonlinear dynamics approach has shown significant changes in symbolic dynamics and time irreversibility indices. The response of the ANS expressed in chronotropic cardiac regulation during and after phototherapy could be characterized by a shift in sympatho-vagal balance towards sympathetic dominance and this modification persists at least $30 \mathrm{~min}$ after phototherapy (Uhrikova et al. 2015).

Reduction up disappearance of HRV was also found in newborns with periventricular hemorrhage, transient reduction was present in cerebral edema (Hornchen et al. 1983, Van Ravenswaaij-Arts et al. 1994, and others) and in children with hydrocephalus. It was found a coupling between intracranial pressure (ICP) and 
RR intervals in patients undergoing hydrocephalus diagnosis (Xiao Hu et al. 2007). Reduction of the HRV in this situation is probably a manifestation of limitated perfusion and function CNS regions involved to cardiac regulation mainly by an increase of intracranial pressure.

Our preliminary results (Uhrikova et al. 2012) show that therapeutic drainage of the hydrocephalus not only decreases the ICP, improves cerebral hemodynamics (confirmed by Doppler sonography), diminishes the size of the brain ventricles but there is also a significant increase of HRV parameters obtained by conventional spectral analysis. It indicates significant improvement of chronotropic cardiac regulation after decrease of the ICP.

Hypoxic ischemic encephalopathy (HIE) is a very severe consequence of the asphyxia in newborns. Recently, whole body controlled hypothermia is used as a preventive-therapeutic method aimed at reducing the consequences of hypoxic - ischemic and subsequent reperfusion injury in asphyctic newborns. It starts almost immediately - to $6 \mathrm{~h}$ postpartum and lasts approximately $72 \mathrm{~h}$. Hypothermia is kept on the body temperature (BT) level approx. $33.5^{\circ} \mathrm{C}$ and after the determined time, the process of the rewarming lasting about $12-15 \mathrm{~h}$ starts.

Little is known about the effects of hypothermia therapy and subsequent rewarming on the heart rate and heart rate variability (HRV) in term newborns with HIE. Lasky et al. (2009) found that for every $1{ }^{\circ} \mathrm{C}$ increase in body temperature the heart rate increases by $9.2 \mathrm{bpm}$, and spectral activities in low and high frequency bands in HRV are decreasing. We found that during the rewarming phase blood pressure decreases and HR gradually rises (Kozar et al. 2015, Kozar 2016). Changes in HRV parameters during rewarming depended on severity of the HIE. In newborns with severe HIE the reduction of the HRV was enhanced, in newborns with moderate HIE the HRV increases during rewarming.

HIE can be associated with reduced HRV, and monitoring HRV may provide useful adjunct information on the severity of brain injury in infants with HIE (Vergales et al. 2014).

\section{Conclusions}

HRV is determined by heritability, gestational and postnatal age, and others. Premature infants have a reduced HRV with dominant activity in low frequency band in spectral (FFT) analysis demonstrating the dominance of the sympathetic system. The dominance persists also later at least in the firsts few months of postnatal life. On the $3 \mathrm{rd}-4$ th postnatal day is significant enhancement of the HRV parameters in newborns.

In HRV measure were only small differences between hypotrophic (SGA) and eutrophic (AGA) newborns of the same gestational and postnatal age, as well as between newborns born by different modes of delivery (spontaneous vaginal, with epidural anesthesia EDA and via sectio cesarea). Different diseases, disorders and their treatment in newborns can be linked with a reduction of HRV and improvement of pathological situations can be followed by the enhancement of the HRV.

Assessment of heart rate variability in neonatology provides information on the maturity of the cardiac chronotropic regulation in early postnatal life, on postnatal adaptation and in pathological cases about possibly dysregulation of cardiac function in newborns, especially in preterm infants.

\section{Conflict of Interest}

There is no conflict of interest.

\section{Acknowledgements}

This work was supported by Projects: VEGA No. 1/0202/16, APVV - 0235-12, "Biomedical Center Martin" ITMS Code 26220220187 and by the project Center of Excellence of Perinatology Research (CEPV).

\section{References}

AARIMAA T, OJA R: Transcutaneous pO2, pCO2 and heart arte patterns during normal postnatal adaptation and respiratory distress. Early Hum Developm 16: 3-11, 1988.

ANDRASYOVA D, KELLEROVA E: Blood pressure and heart rate response to head-up position in full-term newborns. Early Hum Developm 44: 169-178, 1996.

ANDRIESSEN P, OETOMO SB, PETERS C, VERMEULEN B, WIJN PF, BLANCO CE: Baroreceptor reflex sensitivity in human neonates: The effect of postmenstrual age. $J$ Physiol 568: 333-341, 2005.

BENNET L, BOOTH LC, DRURY PP, QUAEDACKERS JS, GUNN AJ: Preterm neonatal cardiovascular instability: does understanding the fetus help evaluate the newborn? Proc Austr Physiol Soc 43: 81-89, 2012. 
BUTERA G, BONNET D, SIDI D, KACHANER J, CHESSA M, BOSSONE E, CARMINATI M, VILLAIN E: Patients operated for tetralogy of Fallot and with non-sustained ventricular tachycardia have reduced heart rate variability. Herz 29: 304-309, 2004.

COHEN G, LAGERCRANTZ H, KATZ-SALAMON M: Abnormal circulatory stress responses of preterm graduates. Pediat Res 61: 329-334, 2007.

CRASSET V, MEZZETTI S, ANTOINE M, LINKOWSKI P, DEGAUTE JP, VAN DE BORNE P: Effects of aging and cardiac denervation on heart rate variability during sleep. Circulation 103: 84-88, 2001.

CURZI-DASCALOVA L, CHRISTOVA E, PEIRANO P, SINGH BB, GAULTIER C, VINCENTE G: Relationship between respiratory pauses and heart rate during sleep in normal premature and full-term newborns. J Developm Physiol 11: 323-330, 1989.

CZIPPELOVA B, CHLADEKOVA L, UHRIKOVA Z, JAVORKA K, ZIBOLEN M, JAVORKA M: Time irreversibility of heart rate oscillations in newborns - Does it reflect system nonlinearity? Biomed Signal Process Control 19: 85-88, 2015.

DANIHEL L, ZAVIAČIČ M, PORUBSKÝ J, HRÚZIK P: Vývoj adrenergnej inervácie srdca človeka (in Slovak). Bratisl Lek Listy 90: 490-494, 1989.

DIPIETRO JA, COSTIGAN KA, PRESSMAN EK, DOUSSARD-ROOSWELT JA: Antenatal origins of individual differences in heart rate. Dev Psychobiol 37: 221-228, 2000.

DIPIETRO JA, BORNSTEIN MH, HAHN CS, COSTIGAN K, ACHY-BROU A: Fetal heart rate and variability: Stability and prediction to developmental outcomes in early childhood. Child Developm 78: 1788-1798, 2007.

DROUIN E, GOURNAY V, CALAMEL J, MOUZARD A, ROZE JC: Assesment of spontaneous baroreflex sensitivity in neonates. Arch Dis Child Fetal Neonatal Ed 76: F108-F112, 1997.

EL-SHEIKH M, BUCKHALT JA: Vagal regulation and emotional intensity predict children's sleep problems. Developm Psychobiol 46: 307-317, 2005.

FELDMAN R: From biological rhythms to social rhythms: Physiological precursors of mother-infant synchrony. Developm Psychol 42: 175-188, 2006.

FYFE KL, YIALLOUROU SR, WONG FY, HORNE RS: The development of cardiovascular and cerebral vascular control in preterm infants. Sleep Med Rev 18: 299-310, 2014.

FYFE KL, YIALLOUROU SR, WONG FY, ODOI A, WALKER AM, HORNE RS: Gestational age at birth affects maturation of baroreflex control. J Pediat 166: 559-565, 2015.

GALLAND BC, TAYLOR BJ, BOLTON DPG, SAYERS RM: Heart rate variability and cardiac reflexes in small for gestational age infants. J Appl Physiol 100: 933-939, 2006.

GODIN PJ, FLEISHER LA, EIDSATH A: Experimental human endotoxemia increases cardiac regularity: results from a prospective, randomized, crossover trial. Crit Care Med 24: 1117-1124, 1996.

GOLDER V, HEPPONSTALL M, YIALLOUROU SR, ODOI A, HORNE RS: Autonomic cardiovascular control in hypotensive critically ill preterm infants is impaired during the first days of life. Early Hum Dev 89: 419-423, 2013.

GONZALES GF, SALIRROSAS A: Pulse oxygen saturation and neurologic assessment in human neonates after vaginal and cesarean delivery. Int J Gynecol Obstetr 63: 63-66, 1998.

GOURNAY V, DROUIN E, ROZE JC: Development of baroreflex control of heart rate in preterm and full term infants. Arch Dis Child Fetal Neonatal Ed 86: F151-F154, 2002.

GRIFFIN MP, MOORMAN JR: Toward the early diagnosis of neonatal sepsis and sepsis-like illness using novel heart rate analysis. Pediatrics 107: 97-104, 2001.

GRIFFIN MP, LAKE DE, O'SHEA TM, MOORMAN JR: Heart rate characteristics and clinical signs in neonatal sepsis. Pediat Res 61: 222-227, 2007.

HARPER RM, HOPPENBROUWERS T, STERMAN MB, MCGINTY DJ, HODGMAN J: Polygraphic studies of normal infants during first six months of life. Heart rate variability as a function of state. Ped Res 10: 945-948, 1976.

HASKOVA K, CZIPPELOVA B, JAVORKA M, ZIBOLEN M, JAVORKA K: Baroreflex sensitivity in premature infants - relation to the parameters characterizing intrauterine and postnatal condition. Physiol Res 66 (Suppl 2): S257-S264, 2017. 
Heart rate variability. Standards of measurement, physiological interpretation, and clinical use. Task Force of the European Society of Cardiology and the North American Society of Pacing and Electrophysiology. Eur Heart J 17: 354-381, 1996.

HORNCHEN H, BETZ R, KOTLAREK F, ROEBRUCK P: Microprocessor-based long term cardiorespirography. II. Status evaluation in term and premature newborns. J Perinat Med 11: 32-42, 1983.

JAVORKA M: Using Some Non-Linear Dynamics Methods to Evaluate Variability of Cardiovascular System Parameters (in Slovak). Habilitation Thesis, Martin, 2006, 110 p.

JAVORKA K, ZAVARSKA L: Oculocardiac reflex in premature newborns (in Slovak). Cesk Pediatr 33: 138-140, 1978a.

JAVORKA K, ZAVARSKA L: The problem of heart rate regulation in premature children with RDS (in Slovak). Cesk Pediat 33: 536-539, 1978 b.

JAVORKA K, TOMORI Z, ZAVARSKA L: Upper airway reflexes in newborns with respiratory distress syndrome. Bull Eur Physiopathol Respir 21: 345-349, 1985.

JAVORKA K, ZAVARSKA L: Zmeny systémového tlaku krvi a kardiorespiračných parametrov u nedonosených novorodencov počas fototerapie (in Slovak). Cesk Pediat 45: 230-232, 1990.

JAVORKA K, CALKOVSKA A, DANKO J, DOKUS K, FUNIAK S, GWOZDZIEWICZ M, JAVORKA M, JAVORKOVA J, KUCHTA M, MISOVICOVA N, ET AL.: Heart Rate Variability: Mechanisms, Evaluation, Clinical Application (in Slovak). Martin, Osveta, 2008, 204 p.

KANTOR L, CURTISOVA V, DUBRAVA L: Development of heart rate variability during the first three days of life. Acta Med Mart 3: 22-29, 2003.

KERO P: Heart rate variation in infants with the respiratory distress syndrome. Acta Paediatr Scand Suppl 250: 1-70, 1974.

KOZAR M, JAVORKA K, JAVORKA M, MATASOVA K, ZIBOLEN M: Changes of cardiovascular regulation during rewarming in newborns undergoing whole-body hypothermia. Neuroendocrinol Letters 36: 101-105, 2015.

KOZAR M: Early Postnatal Development of Cardiorespiratory Functions in Term Newborns (in Slovak). PhD Thesis, Comenius University in Bratislava, Jessenius Faculty of Medicine in Martin, 2016, 117 p.

KUPPER N, WILLEMSEN G, POSTHUMA D, DE BOER D, BOOMSMA DI, DE GEUS EJ: A genetic analysis of ambulatory cardiorespiratory coupling. Psychophysiology 42: 202-212, 2005.

LASKY RE, PARIKH NA, WILLIAMS AL, PADHYE NS, B, SHANKARAN S: Changes in the PQRST intervals and heart rate variability associated with rewarming in two newborns undergoing hypothermia therapy. Neonatology 96: 93-95, 2009.

LEHOTSKA Z, JAVORKA K, JAVORKA M, ZIBOLEN M, LUPTAKOVA A: Heart rate variability in small-for-age newborns during first days of life. Acta Med Mart 7: 10-16, 2007a.

LEHOTSKA Z: Heart Rate Variability in Hypotrophic Term Newborns (in Slovak). PhD Thesis, Comenius University in Bratislava, Jessenius Faculty of Medicine in Martin. 2007b, 90 p.

LONGIN E, GERSTNER T, SCAIBLE T, LENZ T, KONIG S: Maturation of the autonomic nervous system: differences in heart rate variability in premature vs. Term infants. J Perinat Med 34: 303-308, 2006.

MAKAROV L, KOMOLIATOVA V, ZEVALD S, SCHMIDT G, MULLER CA, SEREBRUANY V: QT dynamicity, microvolt $\mathrm{T}$-wave alternans, and heart rate variability during 24-hour ambulatory electrocardiogram monitoring in the healthy newborn of first to fourth day of life. J Electrocardiol 43: 8-14, 2010.

MAULIK D, SAINI V, ZIGROSSI ST: Clinical significance of short-term variability computed from heart-rate waveforms. J Perinat Med 11: 243-287, 1983.

MEHTA SK, SUPER DM, CONNUCK D, SALVATOR A, SINGER L, FRADLEY LG, HARCAR-SEVCIK RA, KIRCHNER HL, KAUFMAN ES: Heart rate variability in healthy newborn infants. Am J Cardiol 89: 50-53, 2002.

MENY RG, CARROLL JL, CARBONE MT, KELLY DH: Cardiorespiratory recordings from infants dying suddenly and unexpectantly at home. Pediatrics 93: 44-49, 1994.

MILLS E: Time course for development of vagal inhibition of the heart in neonatal rats. Life Sci 23: 2717-2720, 1978. 
NAGY E, ORVOS H, BÁRDOS G, MOLNÁR P: Gender-related heart rate differences in human neonates. Ped Research 47: 778-780, 2000.

NISHIDA H, OGUCHI K, HAKU R, MIHARA T, HIRAISHI S, YASHIRO K: Clinical aplicability of neonatal instantaneous heart rate monitoring: Part 2. Asphyxia and variability of instantaneous heart rate. Perinat Med 9 (Suppl 1): 160-161, 1981.

POLSON JW, MCCALLION N, WAKI H, THORNE G, TOOLEY MA, PATON JF, WOLF AR: Evidence for cardiovascular autonomic dysfunction in neonates with coarctation of the aorta. Circulation 113: 2844-2850, 2006.

PORGES SW, DOUSSARD-ROOSWELT JA, STIFTER CE, MCCLENNY BD, RINIOLO TC: Sleep state and vagal regulation of heart periods in human newborn: An extention of the polyvagal theory. Psychophysiology 14: 14-21, 1999.

PORTA A, GUZZETTI S, MONTANO N, FURLAN R, PAGANI M, MALLIANI A, CERUTTI S: Entropy, entropy rate, and pattern clasification as tools to typify complexity in short heart period variability series. IEEE Trans Biomed Eng 48: 1282-1291, 2001.

PORTA A, GUZZETTI S, FURLAN R, GNECCHI-RUSCONE T, MONTANO N, MALLIANI A: Complexity and nonlinearity in short-term heart period variability: comparison of methods based on local nonlinear prediction. IEEE Trans Biomed Eng 54: 94-106, 2007.

PRIETSCH V, MAIER R, SCHMITZ L, OBLADEN M: Heart rate variability increases with successful closure of patent ductus arteriosus in preterm infants. Biol Neonate 61: 142-149, 1992.

RICHARDS JE: Development and stability in visual sustained attention in 14, 20, and 26 week infants. Psychophysiol 26: 422-430, 1989.

RUDOLPH AM: Venous return and cardiac output in the perinatal period. In: Cardiovascular and Respiratory Physiology in the Fetus and Neonate. Colloque INSERM/John Libbey Eurotext Ltd, Montrogue, 1986, pp 15-30.

SINGH JP, LARSON MG, O'DONNELL CJ, TSUJI H, EVANS JC, LEVY D: Heritability of heart rate variability. The Framingham Heart Study. Circulation 99: 2251-2254, 1999.

SPASSOV L, CURZI-DASCALOVA L, CLAIRAMBAULT J, KAUFFMANN F, EISELT M, MEDIGUE C, PEIRANO P: Heart rate and heart rate variability during sleep in small-for-gestational age newborns. Pediat Res 35: 500-505, 1994.

SPERELAKIS N, PAPPANO AJ: Physiology and pharmacology of developing heart cells. Pharmacol Ther 22: 1-39, 1983.

STONE ML, TATUM PM, WEITKAMP JH, MUKHERJEE AB, ATTRIDGE J, MCGAHREN ED, RODGERS BM, LAKE DE, MOORMAN JR, FAIRCHILD KD: Abnormal heart rate characteristics before clinical diagnosis of necrotizing enterocolitis. $J$ Perinatol 33: 847-850, 2013.

THOMAS PW, HASLUM MN, MACGILLIVRAY I, GOLDING MJ: Does fetal heart rate predict subsequent heart rate in childhood? Early Hum Development 19: 147-152, 1989.

TOTH B, BECKER A, SEELBACH-GOBEL B: Oxygen saturation in healthy newborn infants immediately after birth measured by pulse oximetry. Arch Gynecol Obstet 266: 105-107, 2002.

UHRIKOVA Z, KOLAROVSZKI B, JAVORKA K, JAVORKA M, MATASOVA K, KOLAROVSZKA H, ZIBOLEN M: Changes in heart rate variability in a premature infant with hydrocephalus. Am J Perinatol Rep 2: 43-46, 2012.

UHRIKOVA Z, ZIBOLEN M, JAVORKA K, CHLADEKOVA L, JAVORKA M: Hyperbilirubinemia and phototherapy in newborns: Effects on cardiac autonomic control. Early Hum Developm 91: 351-356, 2015.

VAN RAVENSWAAIJ-ARTS C, HOPMAN J, KOLÉE L, STOELINGA G, VAN GEIJN H: Spectral analysis of heart rate variability in spontaneously breathing very preterm infants. Acta Paediat 83: 473-480, 1994.

VEERAPPAN S, ROSEN H, CRAELIUS W, CURCIE D, HIATT M, HEGYI T: Spectral analysis of heart rate variability in premature infants with feeding bradycardia. Pediatric Research 47: 659-662, 2000.

VERGALES BD, ZANELLI SA, MATSUMOTO JA, GOODKIN HP, LAKE DE, MOORMAN JR, FAIRCHILD KD: Depressed heart rate variability is associated with abnormal EEG, MRI, and death in neonates with hypoxic ischemic encephalopathy. Am J Perinatol 31: 855-862, 2014. 
VLK J: Pre-and postnatal development of the autonomic innervation of the heart in rats (in Czech). Cesk Fyziol 38: 199-218, 1989

XIAO HU, NENOV V, VESPA P, BERGSNEIDER M: Characterization of interdepency between intracranial pressure and heart variability signals: A causal spectral measure and a generalized synchronization measure. IEEE Trans Biomed Eng 54: 1407-1417, 2007.

YANG TF, KAO NT, CHAN RC, KUO TBJ, CHEN AJ: Power spectrum analysis of heart arte variability in full-term and preterm infants. Tw J Phys Med Rehabil 35: 127-135, 2007.

YIALLOUROU SR, SANDS SA, WALKER AM, HORNE RS: Postnatal development of baroreflex sensitivity in infancy. J Physiol 588: 2193-2203, 2010.

YIALLOUROU SR, SANDS SA, WALKER AM, HORNE RS: Maturation of heart rate and blood pressure variability during sleep in term-born newborns. Sleep 35: 177-186, 2012.

YIALLOUROU SR, WITCOMBE NB, SANDS SA, WALKER AM, HORNE RSC: The development of autonomic cardiovascular control is altered by preterm birth. Early Hum Dev 89: 145-152, 2013. 